\title{
The effect of work-related factors on the bicycle commute mode choice in the Netherlands
}

\author{
Eva Heinen $\cdot$ Kees Maat $\cdot$ Bert van Wee
}

Published online: 11 April 2012

(C) The Author(s) 2012. This article is published with open access at Springerlink.com

\begin{abstract}
Increasing the number of people cycling to work brings a number of benefits: it can lead to reductions in air pollution and traffic jams, and increases people's physical activity levels. We investigated the extent to which work-related factors influence (1) whether an individual decides to cycle to work, and (2) whether an individual cycles to work every day. It is anticipated that the office culture and colleagues' and employers' attitudes would significantly influence both decisions. These factors are expected to impact the provision of cycling facilities and financial compensation schemes in the workplace. We conducted an Internet survey in 4 Dutch municipalities, gathering data from over 4,000 respondents. The results suggest that the following factors increase the likelihood of being a commuter cyclist: having a positive attitude towards cycling; colleagues' expectations that an individual will cycle to work; the presence of bicycle storage inside; having access to clothes changing facilities; and needing a bicycle during office hours. The presence of facilities for other transport modes, an increase in the commute distance, and the need to transport goods, in turn, reduces the chance that an individual will cycle. Cycling frequency is negatively affected, meanwhile, by an increase in commute distance, a free public transport pass or car parking provided by the employer. These results indicate that an individual's working situation affects the commuting cycling behaviour. The findings
\end{abstract}

\footnotetext{
E. Heinen $(\varangle)$

OTB Research Institute for the Built Environment, Delft University of Technology, PO Box 5030, 2600GA Delft, The Netherlands

e-mail: e.heinen@tudelft.nl

K. Maat

OTB Research Institute for the Built Environment and Faculty of Technology, Policy and Management, Delft University of Technology, Delft, The Netherlands e-mail: c.maat@tudelft.nl

B. van Wee

Faculty of Technology, Policy and Management, Delft University of Technology,

Delft, The Netherlands

e-mail: g.p.vanwee@tudelft.nl
} 
also indicate that (partly) different variables influence an individual's decision to cycle to work, and their decision to cycle every day.

Keywords Bicycle $\cdot$ Commuting $\cdot$ Work culture $\cdot$ Mode choice

\section{Introduction}

Commuting, the journey to and from work, makes a key contribution to economic prosperity, and is an important aspect of travel behaviour in modern societies. In the Netherlands, approximately $30 \%$ of journeys are commuter trips, a percentage that is comparable with that in other western countries. The fact that commuting is mandatory for most employees, and occurs between fixed points at fixed times, however, means that commuter trips are vulnerable to traffic congestion. In addition, motorised transport is a key producer of environmental pollution. Over short distances, the bicycle presents a good alternative to motorised transport, can reduce these negative effects, and can even help to improve public health levels and combat obesity. With this in mind, many governments are encouraging bicycle commuting. For example, recent changes to US tax law (Bicycle Commuter Benefit Act 2009 (US Department of the Treasury (2008)) allow employers to reimburse cycling commuters for bicycle-related expenses. In some cities, meanwhile, such as Davis and Portland, a system of cycle lanes has clearly changed the modal split for commuting in favour of the bicycle.

With a long cycling tradition, positive attitudes towards cycling, and good cycling facilities, the Netherlands has the highest rate of bicycle use in the world. The Dutch Government acknowledges the importance of cycling and bicycle-related policies, and encourages bicycle commuting by for example offering tax benefits over their employers that employees can buy a bicycle tax-free once every 3 years for up to a value of $749 €$. Indeed, encouraging bicycle commuting is a key national policy objective. The Dutch Government has pledged to improve and extend bicycle facilities at railway stations, distributes information about cycling, and until 2010, is providing financial support for the realisation of a national cycling network (Ministry of Transport, Public Works and Water Management 2004).

The Dutch Government requires municipal, regional and provincial authorities to provide proper bicycle facilities and cycling environments, such as bicycle storage facilities that are close to public transport stops, a well-designed bicycle infrastructure, and measures to reduce bicycle theft and improve social security (Ministry of Transport, Public Works and Water Management 2004). Moreover, the Dutch Government has set regional targets for bicycle use in 2010 that, at a minimum, match the 2,000 figures for actual use (Ministry of Transport, Public Works and Water Management 2004). Although central government is positive about encouraging cycling, almost all cycling-related investments in the Netherlands are made at the local or regional levels. The country's decentralised planning system means that the municipal, regional and provincial authorities start from different points, and have different policies and outcomes. Central government provides local government with financing for all transport modes, which can be spent in accordance with local priorities.

Increasing knowledge about the effect of work-related factors on bicycle commuting can help employers and governments to develop policies that encourage bicycle commuting. Increased knowledge can help employers to adapt the incentives that they provide for specific modes of commuting and allow them to benefit from having healthier employees, less demand for parking places, and lower commuting costs. Governments can 
use such information to develop targeted policies to help employers develop bicyclefriendly facilities, and formulate policies to encourage commuters to start cycling to work.

Much research has been conducted into commuting behaviour, and particularly into the role of the car (see, for example: Cervero 2002; Dargay and Hanly 2007; Susilo and Maat 2007). By contrast, bicycle commuting has received limited attention. To date, research have found that an individual's bicycle mode choice can be explained by factors such as weather conditions and climate, socio-economic factors, the distance travelled, and attitudes towards cycling (e.g. Heinen et al. 2011, forthcoming; Gatersleben and Appleton 2007; Parkin et al. 2008; Pucher and Buehler 2006; Rodríguez and Joo 2004; Rietveld and Daniel 2004; Bergström and Magnussen 2003; Dickinson et al. 2003; Stinson and Bhat 2004; Nankervis 1999; Noland and Kunreuther 1995). In studying cycling to work, limited research to date has examined the influence of work-related factors on the individual mode choice decision, although it seems very likely that these factors affect the individual transport mode choice to work.

To address this gap, this paper examines the extent to which work-related factors determine an individual's decision to cycle to work. In order to do so, we design a comprehensive model of bicycle commuting. We assume that bicycle commuting is not only determined by factors such as the built environment, available infrastructure, socio-demographics and the commute distance, but also that attitudes and expectations-not only those of the cyclist, but also those within their social environment, such as the employer's-affect an individual's decision to cycle. On the one hand, certain experiences or perceptions may result in an employee having a negative attitude towards cycling to work, such as the perceived risk of having an accident, sweating, having to wear a particular type of clothing, being rained upon, or having to cycle through an unattractive built environment. Such perceptions may also be positive, such as relaxing after a long day at the office. In addition, an employee may not feel able to cycle, as a car might be needed during work hours, or goods need to be transported. On the other hand, an employee's decision will be influenced by the expectations and attitudes of their employer and co-workers. Office norms, for example, might dictate that employees wear suits and drive company cars when visiting clients. A workplace's commuting culture and mentality will also be revealed by whether it provides financial support for transport costs or facilities at work (bicycle storage, showers); or conversely, a car-friendly policy that reduces the relative attractiveness of cycling to work.

A further aspect in need of greater attention is the definition of bicycle commuting. Most travel studies define mode choice as the mode that is usually taken to work, the mode that is used for the main part of the journey, or the mode that is taken on a particular day. This entails making the implicit assumption that commuters use the same mode of transport every day. While this is not true in general, it is even less true of cyclists, who are more dependent on a number of factors, such as the weather, the need to transport loads, and so on. We therefore analyse how work-related factors influence both full-time and parttime bicycle commuting. A full-time bicycle commuter is defined as someone who cycles to work every working day, while a part-time commuter cycles to work at least once a year. In addition, we limit our analysis to commuters who cycle the entire distance from home to work. We thus do not include commuters who use the bicycle for part of a journey, such as for travelling to the railway station.

The paper is structured as follows. In the next section, a short review of the literature is provided, followed by a conceptual model. Then the research design and process of data collection are described. The last two sections present the research results and conclusions. 


\section{Literature review}

This section identifies the factors that are assumed to influence bicycle use, according to the scientific literature. For a more detailed overview of the literature, see Heinen et al. (2010).

Facilities at work

Whether cycling facilities are available in a workplace reveals an employer's attitude towards modes of commuting. The presence of cycling facilities, such as secure storage, showers and changing rooms, makes cycling more attractive (Abraham et al. 2002). Having access to facilities at the end of a trip is more important for commuters than for other types of cyclists. According to Abraham et al. (2002), secure bicycle parking is the most important facility. Of the different kinds of parking, individual bike lockers are most popular, followed by bicycle enclosures and standard bike racks. Not all cyclists consider secure parking to be equally important. Hunt and Abraham (2007) report that for young cyclists, particularly for under-16s, secure parking is more important than for other age groups. Likewise, people with expensive bicycles tend to value secure parking more highly. Hunt and Abraham (2007) suggest that this is due to the relative value of a bicycle is greater for these two groups. Cyclists also attach positive value to the provision of showers (Abraham et al. 2002; Hunt and Abraham 2007). Interestingly, Abraham et al. (2002) find that cyclists and non-cyclists value the provision of showers to the same extent.

Both Abraham et al. (2002) and Hunt and Abraham (2007) undertook stated preference experiments to achieve these research findings. Although we might expect similar effects when researching actual decisions to cycle, the effects might well differ. The limited number of research studies that has been undertaken using revealed preferences has occasionally produced different results. Stinson and Bhat (2004), for example, who focus on commuting frequency, do not find that the availability of showers or clothing lockers has an effect on cycling frequency. However, de Geus (2007) does find that cyclists tend to have greater access to facilities at work than non-cyclists. Thus to conclude, the current picture is an ambiguous one, and it is unclear whether the research methods used, the country studied or the dependent variable chosen is the reason for this.

Attitudes and norms

It seems that there is a positive correlation between cycling, having a positive attitude towards cycling, and supportive social norms. Dill and Voros (2007), for example, demonstrate that being environmentally aware and having a positive attitude towards cycling increases the likelihood that an individual is a utilitarian cyclist. Moreover, cyclists tend to like cycling, and generally think that cycling is healthy and environmentally friendly (Gatersleben and Appleton 2007). Gatersleben and Appleton (2007) contrast the attitudes held during five different stages of developing as a cyclist, ranging from not even considering being a cyclist, to cycling frequently. Their results show that individuals who have been cycling for a long time, who have just started cycling, or who would be prepared to cycle, have more positive attitudes towards cycling than individuals who would not consider cycling or have just started to consider cycling. Attitudes towards cycling change when people change their mode of transport and start cycling. Gatersleben and Appleton (2007) identified a negative shift in new cyclists' perceptions relating to fitness, fun, being 
outside, and convenience. However, these individuals developed a more positive perception of cycling's flexibility and traffic safety.

Changes in an individual's circumstances can also result in attitudinal change. A longitudinal study conducted by Bamberg et al. (2003) found that introducing free bus passes affected people's attitudes and social norms. Free public transport led to an increase in public transport use and a consequent fall in people's intentions to cycle, although the scheme did not have a significant effect on attitudes to cycling. A similar effect was found in the Netherlands, when cycling rates fell after students were given free access to public transport (Rietveld 2000).

Aside from individual attitudes, people are more likely to cycle if their social environment is positive about cycling. de Geus (2007) found that cyclists tend to receive more frequent support for cycling from their social environments than non-cyclists. Moreover, cyclists are more likely to have a 'cycling buddy' and perceive a more positive social norm which implies that the key individuals in their lives tend to be more positive about them cycling. Additionally, Dill and Voros (2007) found that seeing other cyclists on the street makes people want to cycle more.

\section{Socio-demographic factors}

The impact of socio-demographic factors varies between countries. With respect to gender, Garrard et al. (2008) found that most cyclists tend to be male in countries with low rates of cycling. By contrast, in countries with high cycling rates, such as the Netherlands and Denmark, cycling is more evenly spread over the two genders.

The research findings with respect to the effects of income and age are ambiguous. For example, Witlox and Tindemans (2004), Plaut (2005) and Guo et al. (2007) find that an increase in income has a negative effect on cycling levels. Parkin et al. (2008), meanwhile, conclude that an absence of high incomes in England and Wales is connected with a lower bicycle share for commuting.

\section{Research design}

\section{Conceptual model}

To date, most bicycle research has looked at the effect of personal, spatial and infrastructural variables on cycling (such as distance, for example). However, only limited attention has been paid to (social) work-related factors in particular. Therefore this paper aims to identify the work-related factors of bicycle-commuting decisions. In order to control for personal variables, these are included. Based on the literature review (see "Literature review" section) and analytical reasoning we assume that work-related, socioeconomic and other factors influence an individual's decision to be a commuter cyclists (see Fig. 1). Two examples illustrate the potential significance of work-related factors. First, having a positive, pro-cycling work culture may mean that an employer provides financial incentives for cycling, or bicycle facilities. Second, a work culture that does not provide such incentives, or only provides facilities for other modes of transport, might have a lower share of commuter cycling.

As explained in the introduction, in this study, we define bicycle commuting as cycling the entire distance between home and work. This definition excludes cycling to public transport stops. Our frequency for 'cycling' ranges from cycling to work once a year, to 


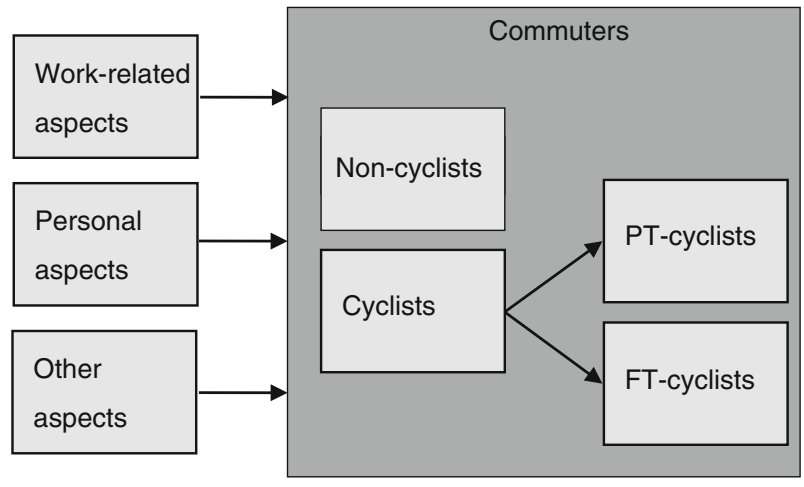

Fig. 1 Conceptual model for bicycle commuting

cycling to work every day. Our study therefore includes those commuters who cycle parttime. The category of cyclists is divided into two groups, full-time cyclists (FT) and parttime cyclists (PT), indicating whether the individual cycles daily, or alternates with other modes of transport. PT thus decide whether or not to cycle to work on a daily basis. So defined, we would expect to see a combination of work-related and socio-economic factors affecting both an individual's decision to commute by bicycle, and his or her daily choice to cycle to work, as reflected in the cycling frequency.

Work-related factors include: having bicycle facilities at the workplace; financial support for commuting; the office dress code; the number of hours worked; office hours; the need for transport during office hours; type of company and contract; and office social norms. Our hypothesis is that these factors correspond with the probability of being a commuter cyclist, and have a positive effect on cycling frequency. On the other hand, the provision of other non-cycling facilities (such as car parking), financial support for other modes of transport, working in a sector or function which is not particularly bicyclefriendly (such as finance), the need to carry goods during office hours, or the need to travel for work, will have a negative impact on commuter cycling.

'Personal factors' include factors as a person's age, gender, education level, vehicle possession, income, household structure, ethnicity, and personal attitudes towards commuting. Previous research suggests that there is a relationship between cycling and socioeconomic variables. Based on this research, we would expect women to cycle as much as men do. In this study, we would expect individuals with higher incomes, non-native Dutch individuals and non-students to cycle less, while we would also expect individuals who have more positive attitudes towards cycling to cycle more. Our expectations with respect to household composition and age are more uncertain, as previous research is ambivalent regarding these factors.

Finally, the 'other factors' category consists of the main commuting distance, and the number of living and working locations. We would expect that with an increase in distance, and consequently with the amount of effort needed, both the probability that people cycle to work and the probability that they cycle every day would decrease. Moreover, we would expect to find fewer (full-time) cyclists among those people who have multiple living or working locations, since this group is more likely to have to make complex journeys. In addition, this group of individuals may have longer commuting distances (which is not controlled for in the analysis), because the distance studied consists of one single distance between the main living- and working locations (see "Variables" section). 
Research approach

To examine the relationship between bicycle commuting and these factors data are needed on the individual mode choice decisions and on personal, attitudinal, work and household characteristics, as well as on the characteristics of their commute travel pattern. A quantitative approach is used to test the relationships between the expected factors and cycling. Existing data sources (e.g. the Dutch National Travel Survey (NTS)) do not provide the required data. In order to generate the necessary data, we collected an internet survey. A web-survey enables data to be collected in an efficient manner: it is fast and cheap, input errors can be avoided, and the use of routing eliminates asking non-applicable questions, thus reducing the burden for the respondent (Berrens et al. 2003; Evans and Mathur 2005). A certain degree of under- or overrepresentation may be expected in web-surveys as not everybody has an Internet connection. Nevertheless, over $94 \%$ of the inhabitants in the Netherlands have Internet excess at home (Statline 2010). Moreover, one can assume that many working people, in particular, are internet-oriented rather than paper-oriented, making this type of survey suited for working people. Thus an Internet survey is likely to fit a survey on commuting. In line with many other recent studies in the area of travel behaviour, and due to the necessary routing in the questionnaire and the focus on commuting, the pros are considered to outweigh the cons (including the risk of bias).

\section{Survey}

In April and May 2008, the Internet survey was conducted among: (1) the employees of several large organisations in Delft and Zwolle, including TU Delft, Delft's main hospital, housing authorities and a receivables management company; and (2) the inhabitants of the municipalities mentioned above. Using address data obtained from the local authorities, a total of 22,000 letters were randomly sent to residents of working age, inviting them to participate (10,000 in Delft, 6,000 in Zwolle, and 3,000 in Pijnacker-Nootdorp and Midden-Delfland). A reminder was sent 1 month later. To the employees, we sent just under 3,500 invitation e-mails. All of the respondents were asked to fill out an online questionnaire, with 40 12-euro lottery tickets being offered as incentives.

The questionnaire was presented as a survey of commuting mode choice. We did not reveal our specific interest in bicycle usage to the respondents, in order to avoid bias towards cyclists or people with positive attitudes toward cycling. In total, 2,929 out of 22,000 residents responded (a rate of $13.3 \%$ ). Of the employees, 1,370 responded from a total of approximately 3,500 e-mail requests (a response rate of $39 \%$ ). Our overall response rate was thus $16.9 \%$.

The mode data of the survey are fairly similar to the Dutch national census data. While there are some differences in respondents' mode choices, in general, similar patterns can be observed (see Tables 1,2). The main difference can be found within the group of respondents stating that they do not use one particular mode of transport to commute, but make a daily choice from multiple forms of transport. This group contains a higher share of cyclists.

Within our dataset, some differences can be observed between the two sample sources (residents or employees). Compared to the residents, employees are more likely to have a middle income, be older, to have a lower level of education, to have one or more cars in their household, to work irregular hours, to have showers, changing facilities, and bicycle storage inside at work, and to work within one kilometre of a highway. We included a dichotomous variable for the sample source to reveal any possible influence on the results. 
Table 1 Mode choice in survey

\begin{tabular}{|c|c|c|c|c|}
\hline & \multicolumn{4}{|l|}{ Own data } \\
\hline & \multicolumn{2}{|c|}{$\begin{array}{l}\text { Always same transport } \\
\text { mode or combination of } \\
\text { transport modes }\end{array}$} & \multicolumn{2}{|c|}{$\begin{array}{l}\text { Different transport or } \\
\text { combinations of transport on } \\
\text { different days }\end{array}$} \\
\hline & Frequency & Percentage & Frequency & Percentage \\
\hline Only car & 1,294 & 50.2 & 1,031 & 61.7 \\
\hline Only bicycle & 648 & 25.1 & 1,017 & 59.1 \\
\hline Only public transport & 133 & 5.2 & 447 & 26.0 \\
\hline Only walking & 61 & 2.4 & 113 & 6.6 \\
\hline Combination of public transport and bicycle & 161 & 6.2 & 231 & 13.4 \\
\hline Combination of car and bicycle & 145 & 5.6 & 248 & 14.4 \\
\hline Combination of car and public transport & 42 & 1.6 & 93 & 5.4 \\
\hline Other & 95 & 3.7 & 261 & 15.2 \\
\hline Total & 2,579 & 100 & 1,720 & \\
\hline Missing & 1,720 & & 2,579 & \\
\hline
\end{tabular}

Table 2 Main mode of transport according Dutch Census travel data (Ministry of Transport, Public Works and Water Management, 2010)

\begin{tabular}{ll}
\hline & $\begin{array}{l}\text { Dutch national data (2007) } \\
\text { All trips } \\
\text { Main mode of transport } \\
\text { (in \%) }\end{array}$ \\
\hline Only car & 57 \\
Only bicycle & 25 \\
Only public transport & 6 \\
Only walking & 10 \\
Combination of public transport & \\
and bicycle & \\
Combination of car and bicycle & \\
Combination of car and public transport & \\
Other & 100 \\
Total & \\
\hline
\end{tabular}

We also included a variable for the municipality, so as to see whether people's home or working municipalities were affecting the results.

\section{Case study area}

This study was carried out in four Dutch municipalities: the medium-sized towns of Delft (approximately 100,000 inhabitants) and Zwolle (approximately 115,000 inhabitants); and two municipalities adjacent to Delft, Midden-Delfland (17,000 inhabitants) and PijnackerNootdorp (38,000 inhabitants). The first reason for selecting Delft and Zwolle was that they have high percentages of (commuting) cyclists, which increased the probability that a large number of cyclists would take part in the survey. These towns are clearly attractive for cycling, and we wanted to discover the apparently positive bicycle characteristics of the 
cities. This does not threaten the study's representativeness, as the selection criteria have been explicitly taken into account as explanatory variables in the analyses, allowing us to control for their effect. Both Delft and Zwolle have higher cycling rates than the Dutch average, with cyclists making $28.2 \%$ and $32.6 \%$ of all trips ending in Delft and Zwolle respectively, and $22.1 \%$ and $27.5 \%$ of commuting trips (MON (Dutch Census data) 2007). The second reason for selecting these particular towns was the potential availability of enough employers with over 100 employees in different branches. In Delft and Zwolle, one can find large educational organisations, local and non-local governmental institutions, public services, industries, and commercial business services. Finally, we expected to gain some advantage from the university's reputation in the City of Delft.

Separate bicycle infrastructure facilities are widely available in all of the selected municipalities. Car ownership rates are as follows: 39 cars per 100 inhabitants in Delft; 49 cars per 100 inhabitants in Zwolle; and 57-58 cars per 100 inhabitants in both PijnackerNootdorp and Midden-Delfland.

\section{Variables}

In this section we describe the variables that are derived from the conceptual model. Table 3 provides an overview of the variables in the analyses.

Attitudes towards bicycle commuting was calculated by summing all the products of beliefs about bicycle commuting and the importance attached. We measured the individual's beliefs in terms of the results of the behaviour (for example, statements such as 'for me, cycling the whole journey to work is mentally relaxing'), on a scale that ranged from 'completely disagree' $(-2)$ to 'completely agree' $(+2)$. The importance was measured of this result for the individual concerned (for example, statements such as 'for me, it is important that my commuting transport mode is mentally relaxing'), on a scale ranging from 'not important at all' (1) to 'very important' (5). A person's attitude was calculated by summing all the products relating to expectations and importance, resulting in a score between -140 and +140 , and had a Cronbach $\alpha$ of 0.897 . We considered the following aspects: environmental friendliness, mentally relaxing, physically relaxing, comfortable, time-saving, flexible, cheap, pleasant, privacy-offering, status-giving, healthy, traffic safety, social safety, and matching with a person's lifestyle.

Social norms in the workplace were measured using the question, 'With which transport mode do you think your colleagues expect you to travel to work?' Respondents could select from all transport modes (car, bicycle, public transport, on foot), and could also indicate if they thought that their colleagues' expectations did not matter. We included four categories in our analysis: by car, by bicycle, by another transport mode, and 'it does not matter'.

The commuting distances are calculated using postal codes for residential and (main) work locations. We used the shortest possible route, not the fastest route by car, on the assumption that the shortest route would be the fastest route for cyclists, and that cyclists usually choose the shortest route.

The following variables were not included in our analysis, although theoretically, one would expect them to have an effect: the number of residential locations; the presence of a train station within one kilometre of the workplace; a high way entrance within one kilometre of the workplace; the availability of bicycle storage outside; being provided with a free bicycle by one's employer; employment type; income; and being a student. We chose not to include these variables on the grounds that they have an insignificant effect. In particular, we had expected that having a free bicycle and income would have an effect. 
Table 3 Variables

\begin{tabular}{|c|c|c|c|}
\hline Description & Values & Mean & St. Dev. \\
\hline \multirow[t]{2}{*}{ Being a cyclist } & No & $60.2 \%$ & \\
\hline & Yes & $39.8 \%$ & \\
\hline \multirow[t]{2}{*}{ Type of cyclist } & Part-time cyclist & $57.5 \%$ & \\
\hline & Full-time cyclist & $42.5 \%$ & \\
\hline Distance in kilometre & $(0-270)$ & 17.0 & 25.3 \\
\hline Attitude towards cycling & $(-140$ to +140$)$ & 33.9 & 41.2 \\
\hline \multirow[t]{2}{*}{ Working hours 12:00-19:00 } & No & $5.3 \%$ & \\
\hline & Yes & $94.7 \%$ & \\
\hline \multirow[t]{2}{*}{ Working hours 0:00-06:30 } & No & $94.8 \%$ & \\
\hline & Yes & $5.2 \%$ & \\
\hline \multirow[t]{3}{*}{ Need to transport goods to work } & Always & $6.2 \%$ & \\
\hline & Sometimes & $29.9 \%$ & \\
\hline & Never & $63.9 \%$ & \\
\hline \multirow[t]{2}{*}{ Needing vehicle during office hours } & No & $52.3 \%$ & \\
\hline & Yes & $47.7 \%$ & \\
\hline \multirow[t]{2}{*}{ Needing a bicycle during office hours } & No & $76.2 \%$ & \\
\hline & Yes & $23.8 \%$ & \\
\hline \multirow[t]{3}{*}{ Number of working locations } & 1 location & $79.3 \%$ & \\
\hline & 2 locations & $12.2 \%$ & \\
\hline & $3+$ locations & $8.6 \%$ & \\
\hline \multirow[t]{2}{*}{ Facility at work: bicycle storage inside } & No & $55 \%$ & \\
\hline & Yes & $45 \%$ & \\
\hline \multirow[t]{2}{*}{ Facility at work: changing facility } & No & $53.2 \%$ & \\
\hline & Yes & $46.8 \%$ & \\
\hline \multirow[t]{2}{*}{ Facility at work: free car parking } & No & $26.3 \%$ & \\
\hline & Yes & $73.7 \%$ & \\
\hline \multirow[t]{2}{*}{ Facility at work: public transport within $500 \mathrm{~m}$} & No & $42.5 \%$ & \\
\hline & Yes & $57.5 \%$ & \\
\hline \multirow[t]{2}{*}{ Bicycle contribution from work } & No & $48.4 \%$ & \\
\hline & Yes & $51.6 \%$ & \\
\hline \multirow[t]{2}{*}{ Free car from work } & No & $88.9 \%$ & \\
\hline & Yes & $11.1 \%$ & \\
\hline \multirow[t]{2}{*}{ Free public transport from work } & No & $87.8 \%$ & \\
\hline & Yes & $12.2 \%$ & \\
\hline \multirow[t]{5}{*}{ Type of organisation } & Agriculture and construction & $14.7 \%$ & \\
\hline & Business & $9.0 \%$ & \\
\hline & Government, education & $50.7 \%$ & \\
\hline & Other services & $14.3 \%$ & \\
\hline & Other & $11.4 \%$ & \\
\hline \multirow[t]{4}{*}{ Type of work } & Employed & $92.1 \%$ & \\
\hline & Own company & $4.0 \%$ & \\
\hline & Volunteer work & $1.6 \%$ & \\
\hline & Mix & $2.2 \%$ & \\
\hline
\end{tabular}


Table 3 continued

\begin{tabular}{|c|c|c|c|}
\hline Description & Values & Mean & St. Dev. \\
\hline \multirow[t]{3}{*}{ Number of hours worked per week } & $0-28$ & $25.6 \%$ & \\
\hline & $28-40$ & $58.6 \%$ & \\
\hline & $>40$ & $15.6 \%$ & \\
\hline \multirow{4}{*}{$\begin{array}{l}\text { Expressed expected opinion of colleagues } \\
\text { regarding how one should travel to work }\end{array}$} & Car & $24.4 \%$ & \\
\hline & Bicycle & $23.9 \%$ & \\
\hline & Other & $8.1 \%$ & \\
\hline & Does not matter & $43.5 \%$ & \\
\hline \multirow[t]{3}{*}{ Having a car available for commuting } & Always & $66.2 \%$ & \\
\hline & Never & $17.6 \%$ & \\
\hline & Sometimes & $16.2 \%$ & \\
\hline \multirow[t]{2}{*}{ Gender } & Male & $55.3 \%$ & \\
\hline & Female & $44.7 \%$ & \\
\hline \multirow[t]{3}{*}{ Education level } & Low & $14.8 \%$ & \\
\hline & Medium & $31.3 \%$ & \\
\hline & High & $53.9 \%$ & \\
\hline \multirow[t]{3}{*}{ Owning a bicycle } & None & $2.0 \%$ & \\
\hline & One bicycle & $12.1 \%$ & \\
\hline & 2 or more & $85.9 \%$ & \\
\hline \multirow[t]{2}{*}{ Owning a car, motor, scooter } & No & $9.6 \%$ & \\
\hline & Yes & $90.4 \%$ & \\
\hline \multirow[t]{2}{*}{ Personal clothing style at work } & Sometimes or always a suit & $12.7 \%$ & \\
\hline & Never a suit & $87.3 \%$ & \\
\hline \multirow[t]{4}{*}{ Age in groups } & $<30$ & $17.0 \%$ & \\
\hline & $30-45$ & $40.1 \%$ & \\
\hline & $45-60$ & $37.9 \%$ & \\
\hline & $60+$ & $5.0 \%$ & \\
\hline \multirow[t]{3}{*}{ Ethnicity } & Dutch & $94.5 \%$ & \\
\hline & Western European & $0.7 \%$ & \\
\hline & Other & $4.8 \%$ & \\
\hline \multirow[t]{4}{*}{ Household composition } & Single & $15.1 \%$ & \\
\hline & Only with partner & $31.7 \%$ & \\
\hline & With children or other family & $50.7 \%$ & \\
\hline & Student house & $2.4 \%$ & \\
\hline \multirow[t]{2}{*}{ Sample source } & Employees & $31.9 \%$ & \\
\hline & Inhabitants & $68.1 \%$ & \\
\hline \multirow[t]{8}{*}{ Survey location } & Delft & $50.0 \%$ & \\
\hline & Zwolle & $24.5 \%$ & \\
\hline & Pijnacker & $6.0 \%$ & \\
\hline & Nootdorp & $3.6 \%$ & \\
\hline & Delfgauw & $3.2 \%$ & \\
\hline & Den Hoorn & $5.6 \%$ & \\
\hline & Maasland & $3.8 \%$ & \\
\hline & Schipluiden & $3.4 \%$ & \\
\hline
\end{tabular}


Univariate analyses indeed show that income affects both dependent variables, as being provided with a free bicycle has a small but significant relationship with being a commuter cyclist, although no effect has been found on frequency. One explanation for this may be that in our model, the influence of income is correlated with and therefore explained by other variables, such as age and the provision of a free car. The effect of being given a bicycle is small if not controlled for the effect of other variables. The absence of a contribution in the final models is probably due to the correlation between bicycle ownership and employer-related factors, such as the availability of bicycle storage.

The municipalities Pijnacker-Nootdorp and Midden-Delfland contain multiple towns: respectively Pijnacker, Nootdorp and Delfgauw, and Den Hoorn, Maasland and Schipluiden. We included all towns separately in our analyses.

Missing data were estimated for the following variables-working hours, income, age, ethnicity, education and function-by applying the 'compute' command, multiple regression analyses, multinomial logit-models and logical sense. Those cases that had incomplete data on distance were excluded from the analysis.

The two dependent variables for the analysis are 'being a commuter cyclist' and 'being a full-time commuter cyclist'. Both dependent variables are dichotomous variables. Therefore, two binary logit models were estimated using Stata.

\section{Results}

\section{Method}

Two binary logit models were applied. The final models were built up including the variables one-by-one. We also did it the other way around- starting from a full mode, deleting one-by-one the insignificant variables starting with the variable which contributed the least to the model (in amount of variance explained) - to make sure the most relevant variables are included in the final models. According to Scott Long and Freese (2006), the McKelvey-Zavoina $\rho^{2}$ is the best approach for explaining the proportion of variation for binary logit models of the available measures of fit. Table 4 sets out the effect of workrelated and socio-economic factors on being a commuter cyclist, as compared with being a non-cyclist. This analysis is based on 4,171 observations, and has a $\rho^{2}$ of 0.81 . Table 5 , in turn, shows the results of the model with respect to choosing to be a full-time or a part-time cyclist and has a $\rho^{2}$ of 0.50 , and included 1,660 cases.

\section{Cycling or not cycling to work}

In this section, the impact of work-related and personal factors is examined on the individual decision to be a commuter cyclist compared to a non-cyclist.

Table 4 shows that the distance commuted and the commuter's attitude towards commuting by bicycle influence an individual's decision to cycle to work. With every additional kilometre, the chance of being a commuter cyclist declines. We also analysed the interaction-effect of gender and distance, which revealed that compared with men, women are less likely to cycle if the distance increases; so, women are more distance-sensitive. Attitudes towards cycling also play an important role in this regard. With every extra point in attitude towards bicycle commuting, the chance of being a commuter cyclist increases.

The results indicate that many work-related factors play an important role in an individual's decision to commute by bicycle. Among these, we found that social norms, 
financial incentives such as the provision of a free car or public transport tickets, having access to facilities at work, the need to carry goods, and the need for transport during working hours, influence an individual's decision to cycle to work. The next five paragraphs discuss these findings in detail.

If an individual's colleagues expect a worker to commute by car or to use a mode of transport other than the car or the bicycle, this individual is less likely to be a cyclist than if the individual's colleagues expect him or her to cycle to work.

A financial incentive offered by the employer that is related to a particular mode of transport has a significant influence on employees' commuting mode choices. An employee who has access to a free car or free public transport is less likely to cycle to work. Contributing to the costs of cycling, however, increases bicycle use. These results are consistent with the findings of Rietveld (2000) and Bamberg et al. (2003), who studied bicycle use among students (see "Literature review" section).

The findings indicate that needing a mode of transport during working hours has a negative effect on bicycle commuting mode choice. People who need a vehicle during working hours, such as a car, are less likely to cycle, while the probability of cycling to work is almost double for those people who need a bicycle. In the Netherlands some employers offer bicycles for use for work purposes. That in spite that people are still more likely to cycle, is probably related to convenience and the possibility of travelling directly from home to the working location, rather than first having to go to one's main work location.

Having access to certain facilities at work increases the likelihood of being a cyclist, namely: bicycle storage inside a building; clothes changing facilities; and having a public transport stop within $500 \mathrm{~m}$ of the workplace. The findings with respect to the first two facility types - storage and changing rooms - are consistent with the literature (Hunt and Abraham 2007; de Geus 2007; see "Literature review" section). The effect of the public transport stop was more unexpected, but this finding might be explained by the fact that combining cycling with public transport on alternate days is more common than combining travelling by car and bicycle. Another explanation could be linked to the employer's attitude towards sustainable transport. If an employer stimulates cycling or public transport use, whether financially or verbally, an employee is more likely to have a positive attitude towards sustainable transport.

The need to carry goods as part of one's work has a negative effect on being a cyclist. People who always or sometimes need to transport goods are much less likely to cycle than people who do not need to transport goods. The Dutch bicycle-promoting literature acknowledges this problem, and suggests as a solution that employers should stimulate employees to limit the need to transport goods to certain days (Fietsberaad 2005).

The results indicate that personal factors also have an effect. Having a bicycle increases the likelihood of cycling to work, while having access to other forms of transport makes it less likely. In particular, possessing a scooter, which competes directly with the bicycle due to its similar distance range, reduces the probability of cycling to work; although so does having every day access to a car. However, people who only sometimes have access to a car are more likely to be commuter cyclists. Moreover, the results suggest that some socioeconomic factors have an impact. Native Dutch people are more likely to be cyclists, for example, than people from non-western European countries. Finally, people under 45 are more likely to be cyclists than those over 60 .

The variable that we added to test the different methods of data collection (employees versus residents) proved to be insignificant, implying that the sample source does not influence the model. Employees are as likely as residents to commute by bicycle. The 
Table 4 Being a commuter cyclist: logit model results

\begin{tabular}{|c|c|c|c|c|}
\hline & & Coef. & Std. Error & $P>|z|$ \\
\hline Distance in kilometres & & -0.100 & 0.01 & $0.000 * *$ \\
\hline Commuter's attitude & & 0.015 & 0.00 & $0.000 * *$ \\
\hline \multirow[t]{3}{*}{$\begin{array}{l}\text { Expressed expected opinion of colleagues } \\
\text { how you should cycle to work }\end{array}$} & $\begin{array}{l}\text { Car } \\
\text { (Bicycle) }\end{array}$ & -0.682 & 0.15 & $0.000 * *$ \\
\hline & Other & -1.452 & 0.19 & $0.000 * *$ \\
\hline & Does not matter & -0.124 & 0.11 & 0.242 \\
\hline \multirow[t]{2}{*}{ Free car from work } & (No) & & & \\
\hline & Yes & -0.509 & 0.20 & $0.011^{*}$ \\
\hline \multirow[t]{2}{*}{ Free public transport from work } & (No) & & & \\
\hline & Yes & -0.566 & 0.15 & $0.000^{*} *$ \\
\hline \multirow[t]{2}{*}{ Bicycle contribution from work } & (No) & & & \\
\hline & Yes & 0.314 & 0.09 & $0.001 * *$ \\
\hline \multirow[t]{2}{*}{ Needing a vehicle during office hours } & (No) & & & \\
\hline & Yes & -0.473 & 0.10 & $0.000 * *$ \\
\hline \multirow[t]{2}{*}{ Needing a bicycle during office hours } & (No) & & & \\
\hline & Yes & 0.627 & 0.11 & $0.000 * *$ \\
\hline \multirow[t]{2}{*}{ Facility at work: bicycle storage inside } & (No) & & & \\
\hline & Yes & 0.270 & 0.09 & $0.003 * *$ \\
\hline \multirow[t]{2}{*}{ Facility at work: clothes changing facility } & (No) & & & \\
\hline & Yes & 0.294 & 0.09 & $0.001 * *$ \\
\hline \multirow[t]{2}{*}{ Facility at work: public transport within $500 \mathrm{~m}$} & (No) & & & \\
\hline & Yes & 0.364 & 0.09 & $0.000 * *$ \\
\hline \multirow[t]{3}{*}{ Need to transport goods to work } & (Always) & & & \\
\hline & Sometimes & 1.262 & 0.32 & $0.000 * *$ \\
\hline & Never & 1.292 & 0.31 & $0.000 * *$ \\
\hline \multirow[t]{2}{*}{ Having a car available for commuting } & Always & -0.528 & 0.13 & $0.000 * *$ \\
\hline & $\begin{array}{l}\text { Sometimes } \\
\text { (Never) }\end{array}$ & 0.184 & 0.15 & 0.214 \\
\hline \multirow[t]{3}{*}{ Owning a bicycle } & (None) & & & \\
\hline & One bicycle & 3.112 & 1.03 & $0.003 * *$ \\
\hline & 2 or more & 3.552 & 1.03 & $0.001^{* *}$ \\
\hline \multirow[t]{2}{*}{ Owning a scooter } & (No) & & & \\
\hline & Yes & -0.619 & 0.14 & $0.000 * *$ \\
\hline \multirow[t]{2}{*}{ Gender } & (Male) & & & \\
\hline & Female & -0.037 & 0.14 & 0.792 \\
\hline \multirow[t]{3}{*}{ Age in groups } & $<30$ & 0.493 & 0.22 & $0.024 *$ \\
\hline & $30-45$ & 0.461 & 0.20 & $0.022 *$ \\
\hline & $\begin{array}{l}45-60 \\
(60+)\end{array}$ & 0.281 & 0.20 & 0.158 \\
\hline \multirow[t]{2}{*}{ Ethnicity } & Dutch & 0.500 & 0.21 & $0.019^{*}$ \\
\hline & $\begin{array}{l}\text { Western European } \\
\text { (Non-western Eu) }\end{array}$ & 0.200 & 0.54 & 0.714 \\
\hline
\end{tabular}


Table 4 continued

\begin{tabular}{lllll}
\hline & & Coef. & Std. Error & $P>|z|$ \\
\hline Groups under whom survey is conducted & Employees & -0.190 & 0.10 & 0.062 \\
Sample source & (Inhabitants) & & & \\
& (Delft) & & & 0.645 \\
& Zwolle & 0.054 & 0.12 & 0.214 \\
& Pijnacker & 0.223 & 0.18 & 0.657 \\
& Nootdorp & 0.098 & 0.22 & $0.021^{*}$ \\
Interaction gender and distance & Delfgauw & 0.552 & 0.24 & 0.917 \\
& Den Hoorn & 0.020 & 0.19 & 0.187 \\
& Maasland & -0.322 & 0.24 & 0.720 \\
\hline
\end{tabular}

Category in brackets is reference

Significance: $* * P<0.01$; $* P<0.05$

variable that we included to control for possible differences between cities proved to have a significant effect. People living in Delfgauw have a higher probability of being commuter cyclists than residents of Delft, a difference that might be due to land-use factors. One specific reason for this may be that Delfgauw is in cycling distance of many locations, and lacks good public transport.

Full-time or part-time commuter cycling

This section focuses on the impact of work-related and personal factors on an individual's decision to commute full-time by bicycle, as opposed to part-time. Table 5 presents the results of the logit model.

Table 5 shows that the commute distance has a negative effect on the probability of being a full-time cyclist. The probability of being a full-time commuter cyclist decreases with every additional kilometre commuted. Testing the interaction effect between gender and distance indicates that with an increase in distance, women are less likely to be FT than men. We can thus conclude that women are more distance-sensitive when it comes to choosing whether to cycle full-time or part-time. Having a more positive attitude towards bicycle commuting increases the probability that an individual cycles to work every day. The likelihood of cycling increases with every point of increase in attitude.

An individual's social and work situation certainly has an effect on the frequency with which they cycle to work. This suggests that employers and co-workers can significantly influence an individual's commuting mode choice.

Of the financial contributions that an employer can offer, only the provision of a free public transport pass has an effect, namely, having free public transport discourages fulltime cycling. This is an interesting finding, as many employers try to be environmentally friendly by offering their employees both a free public transport pass and bicycle-related benefits. Our findings, however, suggest that combining these two fringe benefits is in fact counterproductive as far as cycling is concerned. 
Table 5 Bicycle commuting full-time or part-time: logit model results

\begin{tabular}{|c|c|c|c|c|}
\hline & & Coef. & Std. Err. & $P>|z|$ \\
\hline Distance in kilometres & & 0.887 & 0.02 & $0.000 * *$ \\
\hline Commuter's attitude & & 1.017 & 0.00 & $0.000 * *$ \\
\hline \multirow[t]{2}{*}{ Free public transport from work } & (No) & & & \\
\hline & Yes & 0.531 & 0.15 & $0.028 *$ \\
\hline \multirow[t]{2}{*}{ Facility at work: free car parking } & (No) & & & \\
\hline & Yes & 0.590 & 0.08 & $0.000 * *$ \\
\hline \multirow[t]{2}{*}{ Need to transport goods to work } & Always & 0.133 & 0.11 & 0.011 \\
\hline & $\begin{array}{l}\text { Sometimes } \\
\text { (Never) }\end{array}$ & 0.474 & 0.07 & 0.000 \\
\hline \multirow[t]{2}{*}{ Needing vehicle during office hours } & (No) & & & \\
\hline & Yes & 0.515 & 0.08 & $0.000 * *$ \\
\hline \multirow[t]{2}{*}{ Working hours 12:00-19:00 } & (No) & & & \\
\hline & Yes & 0.499 & 0.14 & $0.014 *$ \\
\hline \multirow[t]{2}{*}{ Working hours 0:00-06:30 } & (No) & & & \\
\hline & Yes & 0.453 & 0.13 & $0.006^{* *}$ \\
\hline \multirow[t]{3}{*}{ Amount of working hours a week } & $(0-28)$ & & & \\
\hline & $28-40$ & 0.632 & 0.13 & $0.024 *$ \\
\hline & $>40$ & 0.928 & 0.26 & 0.791 \\
\hline Personal clothing style at work & $\begin{array}{l}\text { Sometimes or always suit } \\
\text { (Never suit) }\end{array}$ & 0.447 & 0.13 & $0.007 * *$ \\
\hline \multirow[t]{4}{*}{ Type of work } & (Employed) & & & \\
\hline & Own company & 2.570 & 0.98 & $0.014^{*}$ \\
\hline & Volunteer work & 3.050 & 1.71 & $0.047 *$ \\
\hline & Mix & 1.097 & 0.43 & 0.812 \\
\hline \multirow[t]{4}{*}{ Type of organization } & Agriculture and construction & 1.103 & 0.22 & 0.628 \\
\hline & $\begin{array}{l}\text { Business } \\
\text { (Government, education) }\end{array}$ & 0.695 & 0.16 & 0.106 \\
\hline & Other services & 0.652 & 0.14 & $0.040^{*}$ \\
\hline & Other & 0.944 & 0.21 & 0.794 \\
\hline \multirow[t]{3}{*}{ Amount of working locations } & (1 location) & & & \\
\hline & 2 locations & 0.632 & 0.13 & $0.024^{*}$ \\
\hline & $3+$ locations & 0.928 & 0.26 & 0.791 \\
\hline \multirow[t]{2}{*}{ Having a car available for commuting } & Always & 0.265 & 0.05 & $0.000 * *$ \\
\hline & $\begin{array}{l}\text { Sometimes } \\
\text { (Never) }\end{array}$ & 0.363 & 0.07 & $0.000 * *$ \\
\hline \multirow[t]{2}{*}{ Owning a car, motor, scooter } & (No) & & & \\
\hline & Yes & 0.546 & 0.13 & $0.014^{*}$ \\
\hline \multirow[t]{3}{*}{ Household composition } & Single & 1.825 & 0.74 & 0.140 \\
\hline & Only with partner & 2.372 & 0.97 & $0.034 *$ \\
\hline & $\begin{array}{l}\text { With children or other family } \\
\text { (Student house) }\end{array}$ & 2.380 & 0.95 & $0.029 *$ \\
\hline \multirow[t]{2}{*}{ Gender } & (Male) & & & \\
\hline & Female & 0.924 & 0.21 & 0.726 \\
\hline
\end{tabular}


Table 5 continued

Coef. $\quad$ Std. Err. $\quad P>|z|$

\begin{tabular}{lllll}
\hline Interaction gender and distance & (Male) & & & \\
& Female & 0.874 & 0.03 & $0.001^{* *}$ \\
\hline
\end{tabular}

Category in brackets is reference

Significance: $* * P<0,01 ; * P<0,05$

In terms of the role played by workplace facilities, among the variables studied, only the presence of free car parking was found to influence an individual's decision to cycle every day. Not having to pay for car parking reduces the likelihood of being a full-time cyclist, a finding that agrees with claims made in the Dutch bicycle-promoting literature (Fietsberaad 2005).

The results also show that people who always or sometimes need to transport goods are less likely to cycle to work every day than people who do not need to carry goods. Moreover, people who use a vehicle during working hours are less likely to be full-time commuter cyclists.

In contrast to the first analysis outlined in "Cycling or not cycling to work" section, a person's working hours do have an impact on whether they choose to cycle every day. Working between 12:00 and 19:00 and between 0:00 and 06:30 lessens the likelihood of being a full-time cyclist. It is unclear why working between 12:00 and 19:00 would have this effect. The second finding can be explained, however, by the fact that a person working during these hours will need to cycle in the dark, and this is known to have a negative impact on cycling (Stinson and Bhat 2004; Gatersleben and Appleton 2007; see "Literature review" section). The number of hours worked also affects the likelihood of being a full-time cyclist. People who work between 28 and $40 \mathrm{~h}$ are less likely to be fulltime bicycle commuters than people who work between 0 and $28 \mathrm{~h}$. Note that neither commuting distance, nor personal attitudes, nor gender account for this difference. One might have expected to find a link between such factors, as many Dutch part-time workers are women who commute over small distances. Neither is personal income (which was not included in the model) the explanatory variable.

Individuals who always or sometimes wear suits are less likely to be FT than people who never wear suits. In addition, a worker's sector and employment status affect their commuting choices. Individuals working in the educational and governmental sectors are more likely to cycle full-time than individuals working in other service sectors. Moreover, compared to employees, people with their own companies or who do voluntary work are more likely to cycle to work every day. Finally, people who have two working locations are less likely to commute by bicycle every day than people who only have one working location.

Three personal factors were found to influence whether an individual chooses to commute full- or part-time. First, having full- or part-time access to a car lessens the likelihood of being a full-time cyclist, a finding that could reflect the convenient aspects of car ownership. Having a car allows one to avoid cycling in bad weather, for example. The results also show that owning a motorised vehicle of any kind (car, motorbike or scooter) lowers the probability that an individual cycles to work every day. Household composition is the only socio-economic factor that affects whether individuals are FT. People who live with partners or family members are more likely to be FT, compared to people living in a student house or a similar household structure. One possible reason for this might be that 
these individuals have more highly structured, less flexible lives than students or singles, meaning that they perceive travelling by car (instead of by bicycle) to be a better mode of transport that enables them to travel between multiple commitments.

No effect was found for the variable for the data-collection method. This indicates that there is no link between the data-collection method and whether an individual decides to cycle to work every day. In addition, the city in which the survey was conducted was found to have no significant impact on this decision.

\section{Conclusion and implications}

This paper has investigated the extent to which work-related factors affect an individual's decision to be a commuter cyclist, and the frequency with which commuter-cyclists cycle to work. Data were collected by means of an Internet survey of employees and residents in four Dutch municipalities: Delft, Zwolle, Midden-Delfland and Pijnacker-Nootdorp. Our expectation was that cycling would not only be determined by 'hard' factors, such as the built environment, available infrastructure and socio-demographic factors, but also that attitudes and expectations - not only of the cyclists themselves, but also those of the people around them-would affect commuting decisions. These latter expectations and attitudes are reflected in the provision of bicycle-(un)friendly facilities and employer-provided incentive schemes, such as bicycle storage facilities and bicycle contributions. Two binary logit models, the first for being a cyclist and the second for being a full-time or part-time cyclist, offered insights into which work-related factors influence an individual's decision to cycle to work.

This research shows that the bicycle facilities provided by an employer and attitudes in the workplace-whether of the employer, co-workers, or employees—play a key role in determining bicycle commuting mode choice and frequency. This conclusion is based on the following findings. First, an employee who is more positive about bicycle commuting is more likely to be a cyclist and to cycle more frequently. In addition, employees who are expected by their colleagues to commute by car are less likely to cycle to work. These results suggest that by actively promoting cycling among employees and thereby improving employees' attitudes towards bicycle commuting, employers might encourage more people to cycle to work and to do that more frequently. Second, we also found that having bicycle storage inside, changing facilities and a public transport stop within $500 \mathrm{~m}$ of the workplace all increase the chance of being a bicycle commuter. Employers could offer such facilities in order to encourage employees to cycle to work. This finding is in line with the schemes that have already been established by some Dutch companies, which provide bicycle facilities to stimulate cycling. Third, the presence of facilities for other transport modes has a negative effect on bicycle use. Results show that the presence of free car parking is connected with having a smaller number of FT. This finding implies that if increasing cycling is a key policy aim, free car parking should be limited. Fourth, individuals who need to transport goods are less likely to cycle. When such transportation is unavoidable, it will be difficult to commute by bicycle. In this case, an employer could limit the need to transport goods to certain days, thus enabling an employee to cycle to work on other days. The same applies to those employees who need a vehicle during office hours. Our findings show that workers who need a vehicle for work are less likely to commute by bicycle. In order to encourage bicycle commuting, employers could limit necessary car, motorbike or scooter use to certain days. This would make it easier for workers to commute by bicycle. Finally, providing employees with a free car or public 
transport pass was found to have a negative impact on bicycle commuting rates. Employers who specifically wish to stimulate cycling should thus take a critical stance with respect to compensation schemes for public- and car transport. This is an important finding, as in the Netherlands, cycling and use of public transport are often encouraged simultaneously, as both are considered to be sustainable modes of transport.

In addition, we found that as in previous research studies, commuting distance has an important impact on an individual's decision to cycle to work, and the frequency with which they cycle. This means that in order to facilitate bicycle commuting, the distance between an individual's working and living locations should ideally be relatively short. Although it is difficult for policymakers or employees to reduce this distance for current employees, compensation could be offered to those employees who move closer to their workplaces, recruitment could target local employees, and policymakers could offer financial incentives to those changing their residential or work locations.

This research suggests that different variables influence an individual's decision to cycle to work, and the frequency with which he or she cycles. The presence of bicycle storage, changing facilities and travel compensation schemes encourage an individual to cycle, but do not affect frequency. By contrast, the number of hours worked and an individual's working hours only affect whether an individual decides to cycle full-time or part-time. These findings strongly suggest that whether an individual cycles to work is composed of multiple decisions, each of which is made after considering (partially) dissimilar factors. Future research should make this distinction, which would allow policies to be better focused on either encouraging people to take up cycling to work, or to encourage people to cycle to work more often.

Several variables had an insignificant effect, including the number of residential locations; the presence of a train station within one kilometre of the workplace; a high way entrance within one kilometre of the workplace; the availability of bicycle storage outside; being provided with a free bicycle by one's employer; employment type. Some of these variables were to some extent correlated with significant variables, which explain the bicycle mode choice to a larger extent. The insignificant variables are thus less interesting to aim policies at to increase cycling.

The facilities and benefits offered by employers were self-reported by the respondents. Bicycle commuters may be more aware of the bicycle facilities provided, and similarly car commuters may be more aware of car facilities. Nonetheless, we believe that any lack of information about facilities for other transport modes would mainly occur among individuals who do not consider a particular mode of transportation at all. Moreover, we believe that employees are aware of facilities such as free car parking, bicycle parking facilities and showers even if they do not use them. The possible effect of respondents not knowing about certain facilities is therefore assumed to be low.

People's day-to-day choices are further influenced by additional factors, the most important of which is the weather. We were unable to include a weather variable in this research study, as we did not have longitudinal data. Moreover, given that the Netherlands is a small country, there were hardly any differences in climate between the locations surveyed. Additional longitudinal research should thus be conducted in order to test for the effect of weather and other daily determinants on daily bicycle mode choice, such as clothing requirements, or having an appointment on a specific day.

As suggested in the introduction, our findings are of potential significance to both policymakers and employers. Employers could benefit in a number of ways from encouraging more employees to cycle, including: reducing the demand for parking, lower commuting costs, fewer company cars, and healthier employees. Employers could 
encourage cycling by providing car-commuters with bicycles for (short-distance) business trips; providing company cars for business trips during working hours, so that people do not have to commute by car simply because they need a car during working hours; develop an explicitly pro-cycling office culture; and use financial stimuli to encourage bicycle commuting. Policymakers, meanwhile, could use fiscal means to encourage bicycle commuting; develop employer-related policies (voluntary or compulsory); make business parks more bicycle-friendly; and act as role models for other employers, by encouraging cycling among their own employees.

Acknowledgments We would like to thank the anonymous reviewers for their useful comments on the draft version of this paper. A preliminary version of this paper was presented at 12 th International Conference on Travel Behavior Research (IATBR), Jaipur, India and at the Transportation Research Board (TRB), Washington D.C. in 2009.

Open Access This article is distributed under the terms of the Creative Commons Attribution License which permits any use, distribution, and reproduction in any medium, provided the original author(s) and the source are credited.

\section{References}

Abraham, J.E., McMillan, S., Brownlee, A.T., Hunt, J.D.: Investigation of Cycling Sensitivities. Transportation Research Board, Washington, DC (2002)

Bamberg, S., Ajzen, I., Schmidt, P.: Choice of travel mode in the theory of planned behavior: the roles of past behavior, habit, and reasoned action. Basic Appl. Soc. Psychol. 25(3), 175-187 (2003)

Bergström, A., Magnussen, R.: Potential of transferring car trips to bicycle during winter. Transp. Res. Part A 37, 649-666 (2003)

Berrens, R.P., Bohara, A.K., Jenkins-Smith, H., Silva, C., Weimer, D.L.: The advent of Internet surveys for political research: a comparison of telephone and Internet samples. Political Anal. 11(1), 1-21 (2003)

Cervero, R.: Built environments and mode choice: toward a normative framework. Transp. Res. Part D 7(4), 265-284 (2002)

Dargay, J.M., Hanly, M.: Volatility of car ownership, commuting mode and time in the UK. Transp. Res. Part A: Policy Pract. 41(10), 934-948 (2007)

Dickinson, J.E., Kingham, S., Copsey, S., Hougie, D.J.P.: Employer travel plans, cycling and gender: will travel plan measures improve the outlook for cycling to work in the UK? Transp. Res. Part D 8(1), 53-67 (2003)

Dill, J., Voros, K.: Factors Affecting Bicycling Demand: Initial Survey Findings from the Portland Region. Transportation Research Board, Washington, DC (2007)

Evans, J.R., Mathur, A.: The value of online surveys. Internet Res. 15(2), 195-219 (2005)

Fietsberaad: Beleidswijzer Fietsverkeer. Kennis voor Fietsbeleid Gebundeld [Policy Guide for Bicycle Transportation. Compilation of Knowledge for Bicycle Policies] 9, Ede, The Netherlands (2005)

Garrard, J., Rose, G., Lo, S.K.: Promoting transportation cycling for women: the role of bicycle infrastructure. Prev. Med. 46(1), 55-59 (2008)

Gatersleben, B., Appleton, K.M.: Contemplating cycling to work: attitudes and perceptions in different stages of change. Transp. Res. Part A 41(4), 302-312 (2007)

Geus, de B.: Cycling to work. Psychosocial and environmental factors associated with cycling and the effect of cycling on fitness and health indexes in an untrained working population, doctoral dissertation, pp. 1-209. Department of Human Physiology and Sports Medicine, Vrije Universiteit Brussel, Brussel (2007)

Guo, J.Y., Bhat, C.R., Copperman, R.B.: Effect of the Built Environment on Motorized and Non-motorized Trip Making: Substitutive, Complementary, or Synergistic?. Transportation Research Board, Washington, DC (2007)

Heinen, E., Handy, S.L.: Similarities in attitudes and norms, and its effect on the decision to commute by bicycle. Evidence from two bicycle cities: Davis and Delft. Int. J. Sustain. Transp. 6(5), 257-281 (2012)

Heinen, E., Maat, K., van Wee, G.P.: Are longitudinal data unavoidable? Measuring variation in bicycle mode choice. Transp. Res. Rec. (forthcoming, 2012) 
Heinen, E., van Wee, G.P., Maat, K.: Bicycle use for commuting: a literature overview. Transp. Rev. 30(1), 59-96 (2010)

Heinen, E., Maat, K., van Wee, G.P.: The role of attitudes toward characteristics of bicycle commuting on the choice to cycle to work over various distances. Transp. Res. Part D 16(2), 102-109 (2011)

Hunt, J.D., Abraham, J.E.: Influences on bicycle use. Transportation 34(4), 453-470 (2007)

Ministry of Transport, Public Works and Water Management: Nota Mobiliteit. Den Haag, The Netherlands (2004)

Ministry of Transport, Public Works and Water Management (Kennisinstituut voor mobiliteit): Mobiliteitsbalans 2010. Den Haag, The Netherlands (2010)

Nankervis, M.: The effect of weather and climate on bicycle commuting. Transp. Res. Part A 33, 417-431 (1999)

Statline: http://statline.cbs.nl/StatWeb/publication/?DM=SLNL\&PA=37727\&D1=0\&D2=1\&D3=0\&D4=0-1 $\& \mathrm{D} 5=0 \& \mathrm{D} 6=1 \& \mathrm{VW}=\mathrm{T}$, and http://statline.cbs.nl/StatWeb/publication/?DM=SLNL\&PA=71098ned \&D1= $33-40 \& D 2=0-6 \& D 3=a \& H D R=G 1 \& S T B=T, G 2 \& V W=T(2010)$

Noland, R.B., Kunreuther, H.: Short-run and long-run policies for increasing bicycle transportation for daily commuter trips. Transp. Policy 2(1), 67-79 (1995)

Parkin, J., Wardman, M., Page, M.: Estimation of the determinants of bicycle mode share for the journey to work using census data. Transportation 35(1), 93-109 (2008)

Plaut, P.O.: Non-motorized commuting in the US. Transp. Res. Part D 10, 347-356 (2005)

Pucher, J., Buehler, R.: Why Canadians cycle more than Americans: a comparative analysis of bicycling trends and policies. Transp. Policy 13(3), 265-279 (2006)

Rietveld, P.: Non-motorised modes in transport systems: a multimodal chain perspective for the Netherlands. Transp. Res. Part D: Transp. Environ. 5(1), 31-36 (2000)

Rietveld, P., Daniel, V.: Determinants of bicycle use: do municipal policies matter? Transp. Res. Part A 38, 531-550 (2004)

Rodríguez, D.A., Joo, J.: The relationship between non-motorized mode choice and the local physical environment. Transp. Res. Part D 9(2), 151-173 (2004)

Scott Long, J., Freese, J.: Regression Models for Categorical Dependent Variables Using Stata. Stata Press, College Station (2006)

Stinson, M.A., Bhat, C.R.: Frequency of bicycle commuting: internet-based survey analysis. Transp. Res. Rec. 1878, 122-130 (2004)

Susilo, Y.O., Maat, K.: The influence of built environment to the trends in commuting journeys in the Netherlands. Transportation 34(5), 589-609 (2007)

US Department of the Treasury: Publication 15-B Cat. No. 29744 N, for use in 2009 (US Tax law, Bicycle Commuter Benefit Act, effective January 1st 2009), pp. 18-20 (2008)

Witlox, F., Tindemans, H.: Evaluating bicycle-car transport mode competitiveness in an urban environment. An activity-based approach. World Transp. Policy Pract. 10(4), 32-42 (2004)

\section{Author Biographies}

Eva Heinen is an assistant professor on infrastructure planning and mobility at the University of Groningen, faculty of spatial sciences in The Netherlands. She has obtained a PhD degree from Delft University of Technology in 2011 on bicycle commuting.

Kees Maat holds a PhD degree from the Delft University of Technology and is Associate Professor on urban transport at this university. His research is concerned with the study of the built environment, accessibility and travel behaviour, particularly the relationship between them.

Bert van Wee is professor of Transport Policy and head of section Transport and Logistics, Delft University of Technology, The Netherlands 